\title{
Meanings of Being Critically IIl in a Sound-Intensive ICU Patient Room - A Phenomenological Hermeneutical Study
}

\author{
Lotta Johansson $^{*}, 1$, Ingegerd Bergbom ${ }^{1}$ and Berit Lindahl ${ }^{2}$
}

Institute of Health and Care Sciences. The Sahlgrenska Academy, University of Gothenburg, Sweden

${ }^{2}$ School of Health Sciences, Borås University College, Sweden

\begin{abstract}
The aim of this study was to illuminate the meanings of being critically ill in a sound-intensive ICU patient room, as disclosed through patients' narratives. Patient rooms in ICUs are filled with loud activity and studies have revealed sound levels comparable to those of a busy road above the patient's head. There is a risk that the sound or noise is disturbing and at worst a major problem for the patient, but there is a lack of knowledge concerning the patients' own experiences. Thirteen patients were asked to narrate their experiences of the sound environment in ICU patient rooms. The interviews were analyzed using a phenomenological- hermeneutical method inspired by the philosophy of Ricoeur. Six themes emerged from the analysis. Conclusion: The meanings of being a patient in a sound- intensive environment were interpreted as never knowing what to expect next regarding noise, but also of being situated in the middle of an uncontrollable barrage of noise, unable to take cover or disappear. This condition is not to be seen as static; for some patients there is movement and change over time. The meanings indicate that the unpredictable shifts between silence and disturbing sounds stress the critically ill patient and impede sleep and recovery. Our findings indicate the need to reduce disturbing and unexpected sounds and noise around critically ill patients in high-tech environments in order to facilitate wellbeing, sleep and recovery. Nurses have a vital role in developing such an environment.
\end{abstract}

Keywords: Critical illness, health facility environment, patients' experiences, phenomenological hermeneutic, sound.

\section{INTRODUCTION}

Every year thousands of people need to be cared for in intensive care units (ICUs) due to critical illness or injuries. Onset is often acute and unexpected and for some days or more the patient struggles to survive. The location for this struggle is the ICU patient room which is full of loud and intense activity emanating from a large number of health professionals eager to do everything they can to provide the best medical treatment and nursing care. Monitors, infusion pumps, ventilators and dialysis machines are scattered around the patient's bed, each of which generates a wash of sound. Alarms frequently indicate that something is wrong and must be adjusted. The often cavernous room, with poor acoustic control, is hollow-sounding and sometimes chaotic.

This brief description of the aural environment of a traditional patient room in an ICU, indicates that while the rapid development of technology and advanced care has led to increased survival rate for patients in the critical care area it has created an amount of sounds and noise around the patient as well. Today, it is not clear what this means for the critically ill patient. Most of the literature on sound in ICUs reports on sound pressure levels and issues concerning the sources of the sounds. Few studies focus on the in-depth perspective or allow patients to talk about their experiences of being critically ill and surrounded by sounds and noise.

*Address correspondence to this author at the Institute of Health and Care Sciences, University of Gothenburg, Arvid Wallgrens Backe, Box 457, SE40530 Sweden; Tel: + 4631786 6108; Fax: +46 31786 6110;

E-mail: lotta.johansson@fhs.gu.se
Such knowledge is necessary for being able to suggest development and changes of the sound environment.

The concept sound in this paper refers to sounds in general and is used when no psychological perspective is included or when a sound is experienced as pleasant. The concept noise has a negative connotation and is used when the sound is experienced as unpleasant or unwanted.

\section{LITERATURE REVIEW}

As early as in the $19^{\text {th }}$ century, Florence Nightingale (1859) stated that unexpected noise harms the patient [1] and over the years studies have investigated this premise and confirmed that high sound levels and disturbing noise negatively affect both the physical health and psychological wellbeing. A reduction in digestive secretions, a raised heart rate and metabolism and increased oxygen consumption are some of the physiological responses linked to disturbing noise in hospitals $[2,3]$. The psychological effects of environmental noise are found to be numerous: anxiety, changes in mood, emotional stress, nervous complaints, instability, argumentativeness, changes in mood, and increase in social conflicts to mention some [4]. The physical conditions of the ICU patient room have been well research in the last decades. Acoustic studies have shown mean levels of between 50 and $65 \mathrm{db}(\mathrm{A})$ above the patient's head, a level comparable to that of a busy road. There are also peak sound pressure levels (LCpk) [5] reaching 70-85 dB (A) [3, 6-10]. But it is not only the high level of sound that might become disturbing; sound is also experienced psychologically. Noise as a concept has been defined as a loud, unpleasant, unexpected or undesired sound, indicating that the 
experience of noise is subjective and influenced by several factors such as mood, attitudes and personality. A recent quantitative study showed that $40 \%$ of patients recalled noise from the time in the ICU and that $65 \%$ of these reported that they were very disturbed by it [11]. Patients have also mentioned in interviews that the noise in the ICU is extremely disturbing and annoying [11-15]. Moreover, it has been found that about $30-50 \%$ of the sounds are unnecessary $[16,17]$. Despite this plethora of studies the average noise levels inside hospitals have increased over recent decades [18], which means that this issue is not prioritized. One important reason is the lack of knowledge concerning the meaning of being a patient in such a complex sound environment. This study highlights this particular perspective.

Sleep disturbance is common in ICUs [12, 19-22] and has a negative influence on the patients both physiologically and behaviourally. Sleep is influenced by many factors but since noise from machines and alarms are perceived as one of the most stressful stressors by critically ill patients [23] it is likely that noise play an important role [24]. Unfortunately, researchers do not agree about the degree to which noise influences poor sleep in the ICU. Small samples, varying research methods and problems in interpreting the results make it difficult to compare or draw any conclusions from the quantitative studies [21, 25-27]. What is known is that patients in ICUs have extremely abnormal sleep patterns with markedly reduced Rapid Eye Movement (REM) sleep, believed to be the most import stage of sleep [28-30]. It is also known that noise in the ICU patient room disrupts the patients sleep cycle impacting negatively on their wellbeing [11, 12, 23, 31, 32].

One observational study reported that the patients on average reacted 35 times per day to sounds, for example by turning their head towards the sound or opening their eyes [33]. Another study found that alarms occurred on average 6 times an hour and that about 12 tasks per hour were performed in the patient room [17]. This is remarkable since noise-induced stress has been found to interact with other stress to predict poorer sleep [34].

Several studies have reported that many patients experience ICU delirium and delusional memories during their time in the unit [35-37]. ICU delirium, which is an acute confusional state that can develop during an ICU stay [38], increases hospital stay, morbidity and mortality [3942]. No study has yet shown a correlation between high noise levels and confusion or delusional memories but sleep disturbance and delirium share similar mechanisms indicating that a connection exists $[24,43]$.

Critically ill persons' experiences in relation to sounds and noise in ICUs have barely been scientifically investigated. The aim of this study was therefore, to illuminate the meanings of being critically ill in a soundintense ICU patient room, as disclosed through patients' narratives.

\section{METHODOLOGY}

\section{Design}

Stories told by patients' are central in this study. The French philosopher Ricoueur [44] means that a narrative or a told story is related to the lived world of the narrator and contains a direction which makes its wholeness into something greater than the parts. Therefore, in this study the aim is to explain and understand not only the content of the narratives or texts but also the meanings,"what is being talked about" [45] p 127. To acquire this deeper understanding and knowledge a qualitative approach was chosen.

\section{Settings and Participants}

The study setting for this qualitative inquiry was a general ICU at a county/regional hospital located in southwestern Sweden. The ICU has eight beds, and when data were collected, was mostly full to capacity. All participants shared rooms with one or two other patients. The unit uses a light sedation regimen, which means that estimated level for the Motor Activity Assessment Scale (MAAS) is 2-3 [46]. We also observed and identified early signs of ICU delirium using a new, but not yet validated, protocol. The protocol is not a report instrument for assessing ICU delirium but a help for nurses to identify early signs of delirium bedside. This protocol is developed from a study by Granberg-Axell and co-workers [47]. These data are published elsewhere [48]. The nursing staff comprises registered nurses (RNs) with a 1 -year specialist education in intensive care $(70 \%)$ and enrolled nurses (ENs) (30\%). The nurse patient ratio was 1:1 or 1:2. Generally, one RN and one EN work together on each shift and are responsible for two patients. The medical staff consists of one chief intensive care specialist, two other physicians responsible for intensive care treatment and several junior physicians working emergency duty hours.

After discharge, 16 patients recruited using convenience samplings were invited by their allocated nurses to participate in an interview. The following patients were excluded: those treated for head injuries, those who were known to be hard of hearing and those suffering from dementia. At the time of the interview, one refused to participate and two could not be contacted. The final study group thus comprised 13 patients, six women and seven men, aged between 51 and 86 years. Five of the participants needed a ventilator at some time during their stay. The patients' demographic data are shown in Table $\mathbf{1}$.

\section{Data Collection}

Data were collected between May 2007 and July 2008, using tape-recorded interviews 2-35 days after the patients had been discharged from the ICU. The interviews were carried out when and where the patients decided, leading to differences in interview dates (Table 1). The interviewees were asked to narrate their experiences of the sound environment in the ICU patient room. An open-ended question was used, aimed at eliciting the participants' own stories. The researcher started with remarks such as; "I am interested to hear about your experiences and memories of the time in the ICU and especially about your experiences of sound..." Follow- up questions were asked to ensure that the sound perspective was covered and that there were no misunderstandings. All interviews were transcribed verbatim. Although the patients had been seriously ill, the interviews provided thick descriptions concerning individual experiences from critical illness. Two patients did not recall anything from the specific time in ICU, but told about the 
Table 1. Subject Demographics

\begin{tabular}{|c|c|c|c|c|c|c|}
\hline Patient No. & Sex & Age & Diagnosis & ICU Length of Stay in Days & Place of Interview & Time of Interview. Days After Discharge \\
\hline \hline 1 & M & 63 & Pneumonia & 5 & Ward & 3 \\
\hline 2 & M & 63 & Sepsis & 9 & Ward & 26 \\
\hline 3 & F & 81 & Thrombosis & 3 & Telephone & 10 \\
\hline 4 & M & 57 & Pneumonia & 3 & Ward & 14 \\
\hline 5 & M & 57 & Aorticaneurysm & 1 & Home & 5 \\
\hline 6 & F & 60 & Pain treatment & 1 & Ward & 2 \\
\hline 7 & M & 67 & Aorticaneurysm & 1 & Ward & 3 \\
\hline 8 & F & 86 & Rectal cancer surgery & 1 & Ward & 3 \\
\hline 9 & M & 77 & Pulmonaryembolism & 10 & Home & 28 \\
\hline 10 & F & 51 & Guillain-Barre' & 33 & Rehab clinic & 15 \\
\hline 11 & M & 77 & Aorticaneurysm & 4 & Ward & 19 \\
\hline 12 & F & 63 & Whipplessurgery & 1 & Ward & 35 \\
\hline 13 & F & 60 & Pancreatitis & 65 & Ward & \\
\hline
\end{tabular}

time before and after the critical illness. The remaining patients delivered substantial narratives including experiences from sounds and noise in the ICU. 07).

Research Ethics Committee approved the study (No 069-

\section{Data Analysis}

This study used a phenomenological hermeneutical approach, utilizing qualitative research interviews to explore participants' lived experience. The method inspired by Ricoeur [44, 49] but developed and described by Lindseth and Norberg [50], is a well-established method in nursing research [51-53]. It is primarily used in research where the aim is to describe lived experience and to find the essential meaning of a phenomenon. The interpretation process is a dialectic movement back and forth between three steps; naive understanding, structural analysis and comprehensive understanding. The interpretation moves from "what the text says" to "what the text talks about". Lindseth and Norberg [50] encourage the researcher to use an everyday language or poetic words to convey the interpreted meaning. With an intention to provide a further explanation of the actual phenomenon and inspired by the qualitative and narrative analysis [54] the findings of the present study include two composite stories assembled from the patients' narratives. They are meant to move beyond the text itself and disclose various meanings but at the same time reveal an order that is not apparent in the individual interviews. Moreover, the storied narrative form aims to influence and affect the reader leading her/him to arrive at a deeper understanding of the phenomenon [54]. This kind of narrative configuration has been used in several studies in health sciences research [51, 55-57].

\section{RESULTS}

\section{Naïve Understanding}

As a first step in the analysis the researchers read the text several times and try to grasp an initial impression of its meanings as a whole. Our naïve understanding can be expressed as follows: Being a patient in the ICU means being surrounded by unfamiliar and on-going sounds, day and night. It can be a rather comfortable experience where one feels in full control of one's lived situation, generating a feeling of being safe and secure. In contrast, it can be experienced as an episode where control is totally lacking and the predominant feeling is one of helplessness and inability to influence one's own existence. Sometimes, this existence manifests itself as an alternation between these two different feelings. This alternation is beyond the patient's own control and is completely unpredictable.

This subjective premise has to be validated and confirmed. The next step is, therefore, to further examine and interpret the underlying meanings of the text concerning being in full control and lacking control respectively. Structural analyses are then performed regarding the understanding gained from the naive reading and aimed at deepening the understanding of what the text says. The results are presented in language as colloquial as possible [50]

\section{Structural Analysis I: Thematic Analysis}

In this part of the data analysis the interpreted meanings of the individual's experience was elucidated. The whole text was read several times and meaning units concerning being a patient in the ICU sound environment were identified and listed. Thereafter, the meaning units were condensed and abstracted (Table 2). In the next step, narrative passages describing similar meanings were grouped together and subthemes and themes were created (Table 3). Subthemes and themes then became the structure for two composite stories. Subthemes are underlined.

Two of the patients said that they did not remember anything from their time in the ICU, and in the interviews they narrated about times before and after their ICU stay. One of them found it strange not to remember anything from the ICU and suffered because they missed the spring and 
Table 2. Description of the First Part of the Analysis Process Including Examples of Meaning Units, Condensations and Subthemes Aimed at Disclosing Narrative Structures

\begin{tabular}{|c|c|}
\hline Meaning Unit & Condensation \\
\hline $\begin{array}{l}\text { "... and that was because the night became a very hard time in some way... partly because it } \\
\text { was dark and then I guess they didn't want there to be too much activity...." }\end{array}$ & Experiencing the night as dark and quiet \\
\hline $\begin{array}{l}\text { "... In that it was dark... you couldn't see very well... I could in some way... several nights, I } \\
\text { wasn't where I was in the day but somewhere else..." }\end{array}$ & Lacking orientation \\
\hline $\begin{array}{l}\text { "And in addition, in the days there were people around you, you heard other patients and you } \\
\text { could see the staff..." }\end{array}$ & Comparing day and night \\
\hline $\begin{array}{l}\text { "... and I remembered very clearly when the surgeons came into the room, because they had } \\
\text { forgotten to draw my curtain completely, so I saw they were dressed in green clothes and all } \\
\text { that stuff. I didn't want to see that." }\end{array}$ & Being forced to watch and hear the surgeons preparations \\
\hline $\begin{array}{l}\text { "I thought it was hard... I thought, what are they going to do now and why are they here? } \\
\text { And no, I almost got, you know... I thought will they operate in here, in the patient room?" }\end{array}$ & Wondering about what was going to happen \\
\hline "And I thought, I don't want to be here, I don't want to be here... I don't want to see that..." & Wanting to leave \\
\hline
\end{tabular}

Table 3. Structural Analysis I and II: Experiences of Being Critically Ill and Surrounded by Sounds and Noise. Thematic Analysis of 11 Interviews

\begin{tabular}{|c|c|c|}
\hline \multicolumn{3}{|l|}{ Structural Analysis I } \\
\hline Subthemes & Themes & \\
\hline $\begin{array}{l}\text { Feeling safe and secure when relating to earlier } \\
\text { experiences } \\
\text { Feeling secure when hearing the staff work and talk } \\
\text { Feeling secure when hearing the equipment working well } \\
\text { Feeling safe when hearing visitors to the } \\
\text { neighboringpatient }\end{array}$ & $\begin{array}{l}\text { I feel safe and secure when being in a caring } \\
\text { and familiar atmosphere }\end{array}$ & $\begin{array}{l}\text { Composite story } 1 \\
\text { Being at the proper pitch }\end{array}$ \\
\hline $\begin{array}{l}\text { Coping with noise and sound with calmness } \\
\text { Trying to keep calm }\end{array}$ & I am mobilizing mystrength and inner security & \\
\hline $\begin{array}{l}\text { Feeling guilty when unable to be active } \\
\text { Being trapped, surrounded by uncomfortable noise }\end{array}$ & $\begin{array}{l}\text { I feel uncomfortable by being trapped in an } \\
\text { uncontrollable situation }\end{array}$ & \multirow{3}{*}{$\begin{array}{l}\text { Composite story } 2 \\
\text { Being surrounded by piercing sounds }\end{array}$} \\
\hline $\begin{array}{l}\text { Feeling helpless hearing frightening noises from roommate } \\
\text { Being disappointed being left without help } \\
\text { Hearing fragmentary conversations }\end{array}$ & I am an invisible auditor in an imposed drama & \\
\hline $\begin{array}{l}\text { Feeling awkward and uncomfortable when hearing the } \\
\text { staff talk } \\
\text { Feeling afraid and abandoned in the quiet of the night }\end{array}$ & $\begin{array}{l}\text { I am left alone in a strange and demanding } \\
\text { world }\end{array}$ & \\
\hline \multicolumn{3}{|l|}{ Structural Analysis II } \\
\hline Subthemes & Theme & \\
\hline $\begin{array}{l}\text { Facing diffuse sonic experiences } \\
\text { Facing a confusing "movie" } \\
\text { Facing demands related to sounds in dreams }\end{array}$ & $\begin{array}{l}\text { I am struggling with unreal experiences } \\
\text { interwoven with sounds }\end{array}$ & \\
\hline
\end{tabular}

summer of that year. The other patient said that he had accepted his unawareness of everything, including sounds.

The result from the structural analysis $\mathrm{I}$ is presented in the form of two fictive composite stories based on 11 patients' experiences from their time spent in the ICU. Quotations are inserted to validate and illustrate the interpretation of the text.

\section{Composite Story: Being at the Proper Pitch}

\section{Feel Safe and Secure when in a Caring and Familiar Atmosphere}

Gradually, I become more and more aware of where I am and what I have endured. I know that I have been seriously ill and that I am in the ICU. The environment is a little 
strange with unusual sounds, smells and light. I recognize some of the sounds. This is not the first time I've been in an ICU. I had surgery a couple of years ago and I remember what the room looked like, with a lot of machines, monitors and cables around my head. I feel safe and secure when I relate things to these earlier experiences since they help me to understand this environment. I am very weak and tired and I need a lot of help and care. The staff knows this and they are always in the room and around me. I feel secure when I hear the staff work and talk. When I close my eyes I hear them talking to each other, sometimes about the care and treatment but also about private matters. When I hear their low calm voices I know that everything is under control. Now and then I hear the noise of an alarm signal. Rapidly but calmly the staff identifies the source and turn the noise off. Several times they have explained to me the reasons for the alarms so now I feel so safe that I do not even react when I hear the alarms. Instead, when I hear the equipment working well I feel secure. In the background, I can hear the rhythmic sound of my ventilator as an ongoing hum.

2: "I think it (the sound from the ventilator) was some kind of signal that sounded regularly, saying "I am working with this patient with no problem", in some way, I understood that it meant something."

I have also realized that I have some roommates, since I can hear soft sounds behind the thin fabric curtain, sounds of low voices or weak coughing. The sounds are not bothersome. They give the room a kinder and more friendly atmosphere. I also heard once that their family was visiting one of the patients, since I heard them talk and mutter. It did not disturb me at all. When I hear sounds from visitors I feel safe and secure since they are familiar. The only thing that might be disturbing is when they move beds in or out of the room. That is always accompanied by rattling and conversations. Yesterday, a new patient came into the room and for a while there was some activity and noise around him. Fortunately, it lasted only for a short time so I could go back to sleep again.

\section{I am Mobilizing my Strength and Inner Security}

Time passes slowly here and there is a lot of time to think. I can hear everything that happens around me, but I am the kind of person who copes with noise and sound with calmness. I try not to get stressed or upset about things but try to keep calm. I am not interested in what is going on next to me and I try to focus on my own business.

\section{Composite Story: Being Surrounded by Piercing Sounds}

\section{I am Uncomfortable by Being Trapped in an Uncontrollable Situation}

I am not very comfortable about being a patient in the ICU. I know that I need to stay here, as my physical state requires this high-tech care. I am so tired and I do not feel well. This fatigue is hard and sometimes I also feel guilty when I can't be active and participate in different treatments. Around the bed there are machines, monitors and cables, most of them are fixed to my body. I feel trapped, surrounded by uncomfortable noise. Just behind my head I hear the continuous sound from my ventilator. Sometimes the alarm starts ringing and then I wake up rapidly, scared to death that the machine is about to stop. I know that I can't breathe on my own so if the ventilator stops, I will die. There are also other alarms that come and go and since I am not sure what they mean, it is disturbing, not knowing where they come from. Maybe, the signal is an indication of danger.

\section{I am an Invisible Audience in an Imposed Drama}

I have slowly recovered which means that I am aware of almost everything around me. This environment is really unique. There are three of us in this room, three patients with different disorders and each of us seems to be in the same bad condition. This means it is never quiet. Every minute there are unexpected noise from different directions which make it very hard to relax or sleep. Moreover, I feel helpless hearing these frightening noises from my roommates. One patient has severe pneumonia I think, because he coughs all the time and breathes very strangely.

12: "There was a man lying immediately opposite me and I think he was very ill and ... they tried to talk to him but he didn't answer and he breathed very badly. So they had to suction him in his throat regularly. Suddenly they put in large tubes and flushed water and put on big aprons and I don't know what it was. But I heard it so clearly, and I thought it was so frightening".

Another patient screams a lot. I also heard him throw up once and that was awful. Nor can I see any of them. A thin fabric curtain divides our beds so I just hear the different sounds and noises and that means that I am never prepared for them. Every time I fall asleep an unexpected noise wakes me up again. Last night I woke up because of an unexpected noise beside me and something unpleasant happened. Gradually I understood that the patient beside me had become severely ill and needed some kind of treatment. Three physicians had come into the room and I heard everything they said very clearly. I became paralyzed when I realized that I had to stay in the room and listen to all that. I was too tired to get up and leave. I did not even have enough strength to tell the staff about how I felt or ask for help. I just lay there scared and terrified but quiet and calm on the outside. The conversations among the physicians and nurses lasted for what I thought was hours. After a while they started some kind of treatment and I understood that the man might not survive. I was exhausted but I did not know what to do. That night I didn't sleep at all and it was one of the longest nights of my life. Now afterwards I feel disappointed that I was left there without any help.

12: "And then after that he breathed very strangely, it sounded really strange from his...so I guess he was put on a machine too, it sounded so wheezy...(whispering: ) I thought it was so terrible... I think I will never forget it".

Another thing that bothers me is that I often have to hear fragmentary conversations. I hear the staff talk about and with the patient next to me, but I never get the entire story. I am in the middle of the conversation but I am not allowed to ask any questions or give my opinion. I feel like I am invisible. Nor can I talk about it with anyone. I think of these stories over and over again since there is a lot of time for thinking here. 


\section{I am Left Alone in a Strange and Demanding World}

Sometimes, when everything is calm the staff starts chatting and laughing. They are talking so quietly that I do not hear what they are saying but I can hear them laugh. Then I wonder if they are laughing and talking about me. These sounds make me feel really awkward and uncomfortable.

Even if the noises around often disturb me they help me orientate myself. Some nights ago I woke up and did not recognize the surroundings at all. Since I did not hear any familiar sounds I did not know where I was or what time it was. I did not even know if I was alone in the room. It was a terrible experience. I couldn't say anything or move since I was too tired and connected up to cables and the ventilator. For a while I felt really scared and abandoned. Fortunately, after a while one of the nurses appeared which helped me get orientated again.

\section{Structural Analysis II}

After the first structural analysis had been carried out there were sequences left in the text that could not be included in any of the subthemes or themes. Therefore, as a second step we again approached the interviews as a whole and all mentions of the meanings were again extracted and reflected on. This resulted in a new thematic analysis aimed at describing the meanings of experiencing sounds related to unreal experiences (Table 3). Descriptions of the meaning within the theme and subthemes (presented in italics) are presented below, not as a composite story but more as a report.

\section{I am Struggling with Unreal Experiences Interwoven with Sounds}

Being critically ill in the ICU can mean that the sounds become a part of dreams or unreal experiences of various types. Sometimes they consist of diffuse sonic experiences, such as laughter or conversations between family members. They can also take the form of a confusing movie, including both sounds and pictures. Being a part of this kind of movie means shifting between fear and kindness. Hearing sounds as a part of a dream also includes a lack of orientation, which consolidates the feeling of awkwardness. Various strategies are used as a protection. Turning from side to side in the bed or putting the fingers in the ears are examples mentioned. Mostly, these strategies do not help and the patient becomes increasingly frustrated and stressed. It is like being trapped, surrounded by uncontrolled noise. Some sounds in the dreams are also connected with some kinds of orders or demands such as "if you hear that sound, you have to do that". Since the illness makes it difficult for the patient to follow complicated "instructions" these demands are impossible to implement. Being surrounded by these impossible requirements means being completely alone and abandoned since no one understands the situation.

\section{Comprehensive Understanding}

The last part of the phenomenological hermeneutical analysis process aims to integrate the separate parts of the structural analysis into a new whole [49]. Bearing in mind the research question, our pre-understanding, the context of the study, the naïve understanding and the structural analyses, we reflected critically on the phenomenon of being a patient in an ICU patient room, focusing on the sound environment. Here we used our findings and the existing literature to explore and bring to light new insights and understanding.

The following comprehensive understanding emerged: The meaning of being a patient in the sound-intense environment of the ICU patient room could be seen as aimlessly floating in circles with no possibility of taking control over the situation. Moreover, being critically ill and surrounded by unfamiliar sounds could also be seen as never knowing what to expect in the next minute regarding sounds. This condition means feeling on edge for shorter or longer periods, never knowing when there will be an unpredictable sound or noise. It is as if the room expresses a contradictory spatiality which includes both meaningfulness and meaninglessness [58]. The meaning could also be interpreted to mean that the patients are situated in the middle of an uncontrollable barrage of noise, with no protection. They cannot leave or disappear and since the body is unprotected the impact of the noise is brutal and ruthless. No one around seems to understand and the patient lies alone and abandoned. Elisabeth Wederkinck Andersen [59] compares such an assault with torture and calls it the "lesser evil". She means that healthcare professionals may, unintentionally, perform activities which hurt the patient. When the staff controls the time, space, communication and body of the patient it offends the patients dignity and limits their autonomy. The Scandinavian nursing philosopher Kari Martinsen [60] uses a metaphor when she says that a room "sings". She means that the different tones and sounds constitute the atmosphere of a room and set the tone for social interactions in the place. The song can be joyful but also a summons to battle and war, as described in this study. The worst situation occurs when the life-sustaining tone is lost, meaning that life and place has become separated.

\section{DISCUSSION}

In this study the patients' narrated about the sounds and noises in an ICU. They described both positive sound experiences and uncontrollable noise, showing that the sounds and noises in an ICU can be experienced in different ways. The sounds were positive if the nurses explained where they came from and what they meant. Previous experiences of being in an ICU were also very valuable. When the patient feels that he/she is in control it is much easier for him to handle and get accustomed to the surrounding sounds. However, people do not usually have earlier experiences of ICUs. Nor does the majority have the ability or strength to ask about the sounds and noises. Therefore, there is a group of patients in the ICU who are more vulnerable than others concerning surrounding stimuli. This could be one explanation for why so many sounds and noises seem to increase discomfort and trigger feelings of stress and frustration. The connection between stress and surrounding noise is a well-known phenomenon from other research areas [61, 62]. Noise induced stress is a physical and emotional condition that occurs when a person is "unable to ignore, block out or otherwise cope with the unwanted sound, or is able to do so only at a cost" (SIC) [63]. This imbalance between demands and the individual's capacity to cope results in reduced wellbeing but can also 
lead to adverse stress reactions such as disturbances of the homeostasis of the cardiovascular, endocrine, and the immune systems in the body [61]. Good sound reduction arrangements in combination with support from the healthcare staff are, therefore, seen as crucial in helping the patients to regain control over the situation, regarding the sound environment.

One interesting finding was that sounds and noise were interwoven with unreal experiences and dreams and that these dreams compelled the patient to act in different ways. This verifies results from earlier observations [35, 64] and strengthens the argument that disturbing sounds and behavioral changes, such as delirium, are connected $[2,24]$. Lengths of stay, sedation level and severity of illness might impact on the experiences of the patients, but in this study which included a varied sample, all except two patients reported experiences of sounds and noises. A longer stay could mean that the patient had learned to recognize the sounds. More research is needed to discover these connections but it is likely that the patients hear, register and are affected by sounds in a greater degree than we know today.

Sleep is essential to recovery and apart from its importance for many somatic, cognitive and psychological processes [65], sleep shuts down the senses and prevents the body from receiving impressions and sensations; that is it keeps the world out [66]. Despite this, very little has been done in recent years to prevent sleep deprivation in ICUs. Earlier studies focused on the physical aspects of sound and their importance for ICU patients' sleep, but in the present study the patients talked about annoying and disturbing individual sounds as the main reason for sleep disturbance. This implies that even low-intensity sounds can be harmful. Moreover, when one is bedridden and critically ill the world is perceived through the body and its senses and being horizontal in bed affects normal orientation [66]. This means that the ability to perceive is transformed and it is hard to distinguish and understand important sounds. Therefore, an unfamiliar silence is felt to be as frightening as a sudden noise and the environment becomes alien and strange. If we want to help patients in ICUs to recover, promoting sleep is the challenge of the future, and sound control is an important step towards this. The physical environment in the ICU is not designed or built to protect the patient from disturbing sounds; but to meet the needs of the staff and hygienic requirements. The sounds reverberate between bare walls and hard smooth floors increasing the sound levels. Multibed rooms and thin fabric curtains between the beds increase the risk of discomfort, exposing patients' to sounds from others in the room. At worst, noise becomes the norm for patient care in the ICU while quiet remains the exception.

\section{Methodological Reflections}

The strength of the phenomenological hermeneutic method is that the movements between the three steps, naïve reading, structural analysis and comprehensive understanding act as an internal validation. One example of the structural analysis is presented (Table 2) and quotations are used to enhance the credibility and help the reader to decide whether our interpretations are reasonable [67, 68]. We do not claim that we have found the single fundamental truth but we argue that the present results reflect the patients' experiences in a believable way. A description of the context is crucial for understanding [68] and in this study the context is described in detail in the method section. Two of the three authors are intensive care nurses and familiar with the ICU environment and two are familiar with the method used, which consolidated the interpretive process. None of the authors was working at the particular ICU at the time of the interviews, which increased the possibilities of maintaining objectivity. Since the patients themselves decided the time and place, the dates for the interviews differed (2-35 days after discharged). This can be seen as a weakness but since qualitative research aims to discover and clarify a phenomenon from differing views it is important that all kinds of memories concerning sounds are taken into account. The whole text was used in the interpretation. Two of the authors read the interview text several times and interpreted it. The third author was involved in the interpretation process through peer-review seminars and discussions concerning the interview text material. All authors agreed that the findings presented are the most trustworthy understanding of the text.

\section{CONCLUSION}

We can no longer claim that the patients are too critically ill to reflect on the surrounding sounds and noises. Our findings indicate that there is a need to reduce disturbing and unexpected sounds and noises around critically ill patients in high-tech environments in order to facilitate wellbeing, sleep and recovery. When sounds and noises occur unexpectedly and beyond the patient's control, they assault the patient unmercifully and brutally. The unpredictable shifts between silence and disturbing sounds do not create a healing environment for the critically ill patient but instead create stress. The results further indicate that disturbing sounds can be connected with delusional memories in the ICU but more research is needed to verify this premise.

\section{ACKNOWLEDGEMENT}

Declared none.

\section{CONFLICT OF INTEREST}

The authors declare that they have no competing interests.

\section{REFERENCES}

[1] Nightingale F. Notes on Nursing: What It Is and What It Is Not London: Gerald Duckworth Ltd 1859.

[2] Christensen M. The physiological effects of noise: considerations for intensive care. Nurs Crit Care 2002; 7(6): 300-5.

[3] Bailey E, Timmons S. Noise levels in PICU: an evaluative study. Paediatr Nurs 2005; 17(10): 22-6.

[4] WHO. World Health Organization. Guidelines for Community Noise. Outcome of the WHO meeting held in London, United Kingdom. Berglund B, Lindvall T, Geneva 1999.

[5] Speaks CE. Introduction to Sound: Acoustics for the Hearing and Speech Sciences. San Diego, CA: Singular Publishing group 1999.

[6] Kam PC, Kam AC, Thompson JF. Noise pollution in the anaesthetic and intensive care environment. Anaesthesia 1994; 49(11): 982-6.

[7] Christensen M. Noise levels in a general intensive care unit: a descriptive study. Nurs Crit Care 2007; 12(4): 188-97.

[8] Ryherd EE, Persson WK, Ljungkvist L. Characterizing noise and perceived work environment in a neurological intensive care unit. J Acoust Soc Am 2008; 123(2): 747-56. 
[9] Akansel N, Kaymakci S. Effects of intensive care unit noise on patients: a study on coronary artery bypass graft surgery patients. $\mathrm{J}$ Clin Nurs 2008; 17(12): 1581-90.

[10] Lawson N, Thompson K, Saunders G, et al. Sound intensity and noise evaluation in a critical care unit. Am J Crit Care 2010; 19(6): e88-98; quiz e9.

[11] Hofhuis JG, Spronk PE, van Stel HF, Schrijvers AJ, Rommes JH, Bakker J. Experiences of critically ill patients in the ICU. Intensive Crit Care Nurs 2008; 24(5): 300-13.

[12] Granja C, Lopes A, Moreira S, Dias C, Costa-Pereira A, Carneiro A. Patients' recollections of experiences in the intensive care unit may affect their quality of life. Crit Care 2005; 9(2): R96-109.

[13] Lof L, Berggren L, Ahlstrom G. Severely ill ICU patients recall of factual events and unreal experiences of hospital admission and ICU stay and 12 months after discharge. Intensive Crit Care Nurs 2006; 22(3): 154-66.

[14] Almerud S, Alapack RJ, Fridlund B, Ekebergh M. Of vigilance and invisibility-being a patient in technologically intense environments. Nurs Crit Care 2007; 12(3): 151-8.

[15] Wang K, Zhang B, Li C, Wang C. Qualitative analysis of patients' intensive care experience during mechanical ventilation. J Clin Nurs 2009; 18(2): 183-90.

[16] Kahn DM, Cook TE, Carlisle CC, Nelson DL, Kramer NR, Millman RP. Identification and modification of environmental noise in an ICU setting. Chest 1998; 114(2): 535-40.

[17] Gorges M, Markewitz BA, Westenskow DR. Improving alarm performance in the medical intensive care unit using delays and clinical context. Anesth Analg 2009; 108(5): 1546-52.

[18] Busch-Vishniac IJ, West JE, Barnhill C, Hunter T, Orellana D, Chivukula R. Noise levels in Johns Hopkins Hospital. J Acoust Soc Am 2005; 118(6): 3629-45.

[19] Cooper AB, Thornley KS, Young GB, Slutsky AS, Stewart TE, Hanly PJ. Sleep in critically ill patients requiring mechanical ventilation. Chest 2000; 117(3): 809-18.

[20] Freedman NS, Gazendam J, Levan L, Pack AI, Schwab RJ. Abnormal sleep/wake cycles and the effect of environmental noise on sleep disruption in the intensive care unit. Am J Respir Crit Care Med 2001; 163(2): 451-7.

[21] Redeker NS. Challenges and opportunities associated with studying sleep in critically ill adults. AACN Adv Crit Care 2008; 19(2): 17885.

[22] Kamdar BB, Needham DM, Collop NA. Sleep deprivation in critical illness: its role in physical and psychological recovery. J Intensive Care Med 2012; 27(2): 97-111.

[23] Hweidi IM. Jordanian patients' perception of stressors in critical care units: a questionnaire survey. Int J Nurs Stud 2007; 44(2): 227-35.

[24] Figueroa-Ramos MI, Arroyo-Novoa CM, Lee KA, Padilla G, Puntillo KA. Sleep and delirium in ICU patients: a review of mechanisms and manifestations. Intensive Care Med 2009; 35(5): 781-95.

[25] Tembo AC, Parker V. Factors that impact on sleep in intensive care patients. Intensive Crit Care Nurs 2009; 25(6): 314-22.

[26] Bosma KJ, Ranieri VM. Filtering out the noise: evaluating the impact of noise and sound reduction strategies on sleep quality for ICU patients. Crit Care 2009; 13(3): 151.

[27] Xie H, Kang J, Mills GH. Clinical review: The impact of noise on patients' sleep and the effectiveness of noise reduction strategies in intensive care units. Crit Care 2009; 13(2): 208.

[28] Honkus VL. Sleep deprivation in critical care units. Crit Care Nurs Q 2003; 26(3): 179-89; quiz 90-1.

[29] Cabello B, Thille AW, Drouot X, et al. Sleep quality in mechanically ventilated patients: comparison of three ventilatory modes. Crit Care Med 2008; 36(6): 1749-55.

[30] Hardin KA. Sleep in the ICU: potential mechanisms and clinical implications. Chest 2009; 136(1): 284-94.

[31] Novaes MA, Knobel E, Bork AM, Pavao OF, Nogueira-Martins LA, Ferraz MB. Stressors in ICU: perception of the patient, relatives and health care team. Intensive Care Med 1999; 25(12): 1421-6.

[32] Gabor JY, Cooper AB, Crombach SA, et al. Contribution of the intensive care unit environment to sleep disruption in mechanically ventilated patients and healthy subjects. Am J Respir Crit Care Med 2003; 167(5): 708-15.

[33] Merilainen M, Kyngas H, Ala-Kokko T. 24-hour intensive care: an observational study of an environment and events. Intensive Crit Care Nurs 2010; 26(5): 246-53.

[34] Topf M, Thompson S. Interactive relationships between hospital patients' noise-induced stress and other stress with sleep. Heart Lung 2001; 30(4): 237-43.

[35] Granberg A, Bergbom IE, Lundberg D. Acute confusion and unreal experiences in intensive care patients in relation to the ICU syndrome. Part II. Intensive Crit Care Nurs 1999; 15(1): 19-33.

[36] Ringdal M, Johansson L, Lundberg D, Bergbom I. Delusional memories from the intensive care unit- experienced by patients with physical trauma. Intensive Crit Care Nurs 2006; 22(6): 34654.

[37] Van Rompaey B, Elseviers MM, Schuurmans MJ, ShortridgeBaggett LM, Truijen S, Bossaert L. Risk factors for delirium in intensive care patients: a prospective cohort study. Crit Care 2009; 13(3): R77.

[38] Deli-rium and Cognitive Impairment Study Group. Nashville Vanderbilt University Medical Center 2011. Available at: www.mc.vanderbilt.edu/icudelirium/index.html [cited 2011].

[39] Ely EW, Shintani A, Truman B, et al. Delirium as a predictor of mortality in mechanically ventilated patients in the intensive care unit. JAMA 2004; 291(14): 1753-62.

[40] Thomason JW, Shintani A, Peterson JF, Pun BT, Jackson JC, Ely EW. Intensive care unit delirium is an independent predictor of longer hospital stay: a prospective analysis of 261 non-ventilated patients. Crit Care 2005; 9(4): R375-81.

[41] Girard TD, Pandharipande PP, Ely EW. Delirium in the intensive care unit. Crit Care 2008; 12(Suppl 3): S3.

[42] Pisani MA, Kong SY, Kasl SV, Murphy TE, Araujo KL, Van Ness $\mathrm{PH}$. Days of delirium are associated with 1-year mortality in an older intensive care unit population. Am J Respir Crit Care Med 2009; 180(11): 1092-7.

[43] Weinhouse GL, Schwab RJ, Watson PL, et al. Bench-to-bedside review: delirium in ICU patients - importance of sleep deprivation. Crit Care 2009; 13(6): 234.

[44] Ricoeur P. Hermeneutics and the human sciences. Essays on language, action and interpretation. Translated by Thompson JB, First published in 1981, ed. Paris and Cambridge: Editions de la Maison des Sciences de l'homme and Cambridge University Press 1998.

[45] Ricoeur P, Ed. From Text to Action. Original title: Du Text a' l'action Essais d'hermeneutique II. 1986. Translated by Kathleen Blamey and John B. Thompson. London, New York: Continuum 2008.

[46] Devlin JW, Boleski G, Mlynarek M, et al. Motor activity assessment scale: a valid and reliable sedation scale for use with mechanically ventilated patients in an adult surgical intensive care unit. Crit Care Med 1999; 27(7): 1271-5.

[47] Granberg-Axell A, Bergbom I, Lundberg D. Clinical signs of ICU syndrome/delirium: an observational study. Intensive Crit Care Nurs 2001; 17(2): 72-93.

[48] Johansson L, Bergbom I, Persson Waye K, Ryherd EBL. The sound environment in an ICU patient room- a content analysis of sound levels and patient experiences. Intensive Crit Care Nurs 2012; [Epub ahead of print].

[49] Ricoeur P. Interpretation Theory: Discourse and the Surplus of Meaning. Fort Worth: Texas Christian University Press 1976.

[50] Lindseth A, Norberg A. A phenomenological hermeneutical method for researching lived experience. Scand J Caring Sci 2004; 18(2): 145-53.

[51] Sandman BP, Rasmussen BH. On being dependent on home mechanical ventilation: depictions of patients' experiences over time. Qual Health Res 2006; 16(7): 881-901.

[52] Fridh I, Forsberg A, Bergbom I. Close relatives' experiences of caring and of the physical environment when a loved one dies in an ICU. Intensive Crit Care Nurs 2009; 25(3): 111-9.

[53] Ringdal M, Plos K, Bergbom I. Memories of being injured and patients' care trajectory after physical trauma. BMC Nurs 2008; 7: 8.

[54] Polkinghorne DE. Narrative configuration in qualitative analysis. Qual Stud Educ 1995; (8): 5-23.

[55] Edvardsson D, Holritz RB, Kohler RC. Ward atmosphere of horror and healing: a comparative analysis of narrative. Health 2003; 7 (4): 377-96. 
[56] Josephsson S, Asaba E, Jonsson H, Alsaker S. Creativity and order in communication: implications from philosophy to narrative research concerning human occupation. Scand J Occup Ther 2006; 13: 86-93.

[57] McCance TV, McKenna HP, Boore JR. Exploring caring using narrative methodology: an analysis of the approach. J Adv Nurs 2001; 33(3): 350-6.

[58] Lassenius E. Rummet i vårdandets värld (The space in the world of caring) Åbo: Åbo Academy 2005.

[59] Wederkinck AE. Den store og den lille ondskab (The greater and the lesser evil). Sygeplejersken 2006; 1: 41-4.

[60] Martinsen K. Care and vulnerability. Oslo: Akribe; 2006.

[61] Prasher D. Is there evidence that environmental noise is immunotoxic? Noise Health 2009; 11(44): 151-5.

[62] Seidman MD, Standring RT. Noise and quality of life. Int J Environ Res Public Health 2010; 7(10): 3730-8.

[63] Belojevic G, Jakovljevic BVS. Noise and mental performance : Personality attributes and noise sensitivity. Noise Health 2003; 6:
77-89. Available from: http://wwwnoiseandhealthorg/textasp?2003/ 6/21/77/31680 [cited 2010 May 27]

[64] Granberg A, Bergbom EI, Lundberg D. Patients' experience of being critically ill or severely injured and cared for in an intensive care unit in relation to the ICU syndrome. Part I. Intensive Crit Care Nurs 1998; 14(6): 294-307.

[65] Brand S, Kirov R. Sleep and its importance in adolescence and in common adolescent somatic and psychiatric conditions. Int J Gen Med 2011; 4: 425-42.

[66] Fredriksen ST, Ringsberg KC. Living the situation- stress experiences among intensive care patients. Intensive Crit Care Nurs 2007; 23(3): 124-31.

[67] Whittemore R, Chase SK, Mandle CL. Validity in qualitative research. Qual Health Res 2001; 11(4): 522-37.

[68] Lincoln YS, Guba E. Naturalistic Inquiry. Beverly Hills: Sage Publications 1985

(C) Johansson et al.; Licensee Bentham Open.

This is an open access article licensed under the terms of the Creative Commons Attribution Non-Commercial License (http://creativecommons.org/licenses/by-nc/3.0/) which permits unrestricted, non-commercial use, distribution and reproduction in any medium, provided the work is properly cited. 